\title{
RESIDENCE-TIME DISTRIBUTION OF AIR FLOW IN A SPRAY DRYING CHAMBER
}

\author{
Hiromoto USUI, YuJI SANO, YoshihIRo YANAGIMOTO AND KeIJI KATO \\ Department of Chemical Engineering, Yamaguchi University, Ube 755
}

Key Words : Drying, Spray Dryer, Residence-Time Distribution, Peclet Number

Residence-time distribution in a spray dryer is very useful for the analysis of drying of atomized droplets. Also, for better understanding of spray dryer performance, it is most desirable to obtain the air flow characteristics in a spray-drying chamber. Keey and $\mathrm{Pham}^{2)}$ reported the residence-time distribution of air in a tall spray chamber. Recently, Pinilla et $a l^{3)}$ measured the axial dispersion characteristics for both air and liquid droplets in a countercurrent spray column. Except for these reports, it is very hard to find such data in the literature. Thus, it was intended in this work to measure the residence-time distribution of air flow in a spray dryer. The authors have reported the turbulent flow characteristics in a spraydrying chamber ${ }^{4}$ which can be thought of as a prototype model of one of the representative commercial dryers. Using the same experimental apparatus, data on the residence-time distribution for air, determined from an analysis of the response to air temperature perturbation, are reported in this work.

\section{Experimental}

A schematic diagram of experimental apparatus is shown in Fig. 1. A detailed explanation about the spray-drying chamber used in this work has been given in the previous paper. ${ }^{4)}$ The atomizer was detached from the spraying chamber, and no liquid was sprayed in this experiment.

The residence-time distribution of air in the spraydrying chamber was measured by means of the measurement of impulse response of air temperature. For the measurement of temperature response in this apparatus, thermocouples were set both at inlet and outlet sections. Gate A was opened to accomplish a steady air flow at room temperature. Then, gate A was closed in an instant, and gate $\mathrm{B}$ was opened simultaneously. Hot air (around $35^{\circ} \mathrm{C}$ higher than room temperature) began to flow at this instant. After a very short time (around half a second), gate $\mathrm{A}$ was opened again, and gate B was closed simultaneously.

Received February 28, 1985. Correspondence concerning this article should be addressed to H. Usui. Y. Yanagimoto is now with Sanyo Kasei Co., Ltd., Kyoto 605. K. Kato is now with Toyo Netsukogyo Co., Ltd., Hiroshima 730.
This procedure gives an incomplete impulse change of inlet air temperature. Both the inlet and outlet temperatures were detected by thermocouples, and after the signals were A-D converted the temperature response was analyzed by a TEAC PS- 80 microcomputer system. As the response time of the temperature-measuring system was shorter than $0.1 \mathrm{~s}$, the delay in temperature measuring was neglected in this work.

\section{Experimental Results and Discussion}

Typical impulse response data are shown in Fig. 2. As is clearly observed from this diagram, the input signal is not exactly an impulse signal. So the transfer function of the spray dryer was determined from the ratio of numerically Laplace-transformed output signal to that of input signal. The transfer function was simulated, using the model of a series combination of a time delay element and a first-order element given by

$$
G(s)=\frac{e^{-L s}}{1+T s}
$$

The values of $L$ and $T$ for each run based on Eq. (1) are shown in Table 1. Three repeated experiments were carried out for each inlet velocity. Mean values of these runs are shown in Table 1. The ratios of the

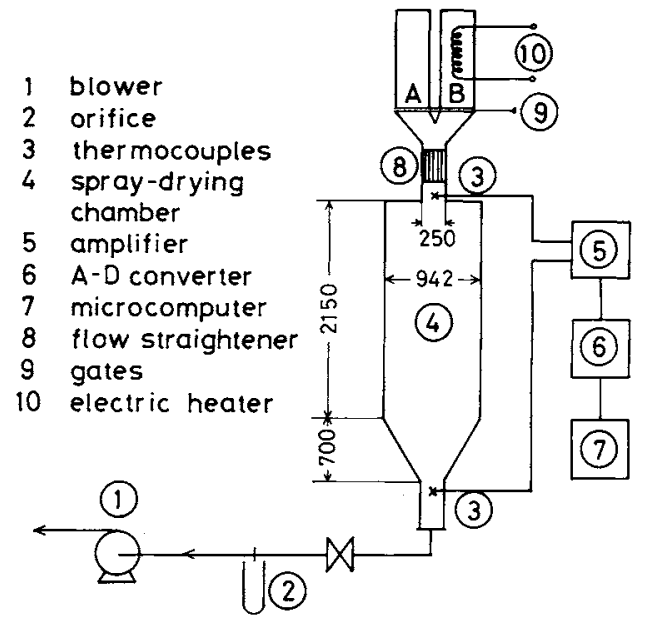

Fig. 1. Experimental apparatus. 
Table 1. Experimental results for measurements of Peclet number

\begin{tabular}{|c|c|c|c|c|}
\hline $\begin{array}{c}U_{0} \\
{[\mathrm{~m} / \mathrm{s}]}\end{array}$ & $\begin{array}{c}U \\
{[\mathrm{~m} / \mathrm{s}]}\end{array}$ & $\begin{array}{c}L \\
{[\mathrm{~s}]}\end{array}$ & $\begin{array}{c}T \\
{[\mathrm{~s}]}\end{array}$ & $\begin{array}{c}P e \\
{[-]}\end{array}$ \\
\hline 9.53 & 1.74 & 0.6 & 1.1 & 3.0 \\
\hline 9.32 & 1.41 & 0.7 & 1.4 & 2.7 \\
\hline 8.08 & 1.23 & 0.8 & 1.6 & 2.7 \\
\hline 7.78 & 1.02 & 0.8 & 2.1 & 2.1 \\
\hline 7.39 & 1.09 & 0.8 & 1.9 & 2.4 \\
\hline 6.42 & 0.92 & 1.0 & 2.2 & 2.4 \\
\hline 6.17 & 0.92 & 1.1 & 2.0 & 2.5 \\
\hline 5.16 & 0.84 & 1.1 & 2.4 & 2.5 \\
\hline 4.57 & 0.76 & 1.3 & 2.6 & 2.7 \\
\hline 4.23 & 0.63 & 1.3 & 3.3 & 2.2 \\
\hline
\end{tabular}

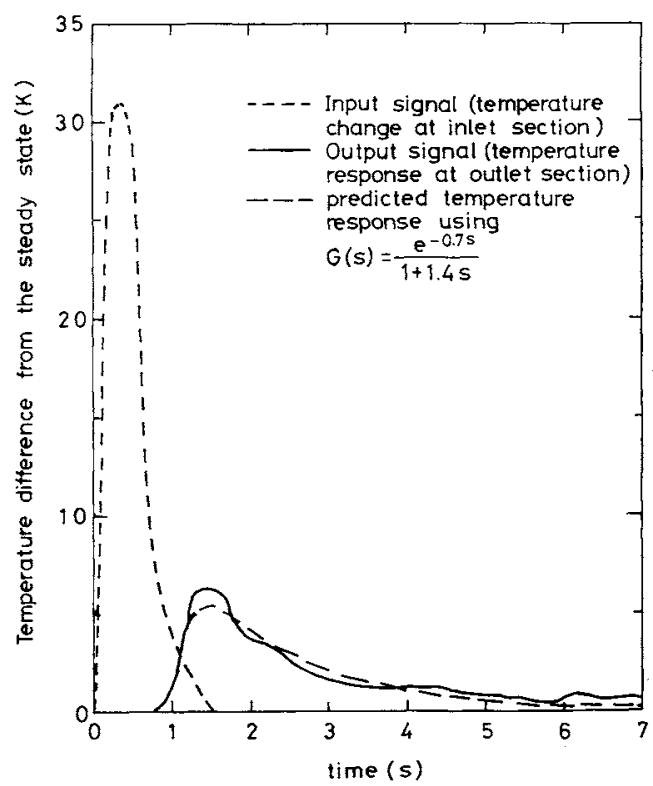

Fig. 2. Response of outlet temperature to pseudo-impulse change of inlet air temperature at $U_{0}=9.32 \mathrm{~m} / \mathrm{s}$.

square root of standard deviation to the averaged values were $2.7 \%$ and $4.2 \%$ for $L$ and $T$, respectively. The product of $G(s)$ and the Laplace-transformed input signal was inverse-Laplace transformed to give the temperature response curve at the outlet section. The predicted result is shown by the broken line in Fig. 2, and shows good agreement with the observed data.

Eguchi $^{1)}$ has rationalized the relationship between the back-mixing diffusion model and the series combination model of a piston flow and perfect mixing given by Eq. (1). Referring to the numerical result given by Eguchi, the Peclet number was calculated from the values of $L$ and $T$ in the series combination model given by Eq. (1). The results are shown in Table 1 and Fig. 3 with the experimental data given by Keey and $\mathrm{Pham}^{2)}$ and Pinilla et al. ${ }^{3)}$ The characteristic velocity, $U$, is defined as $U=H /(L+T)$. This velocity corresponds roughly to the averaged velocity across the cross section of a spray chamber. As the definition

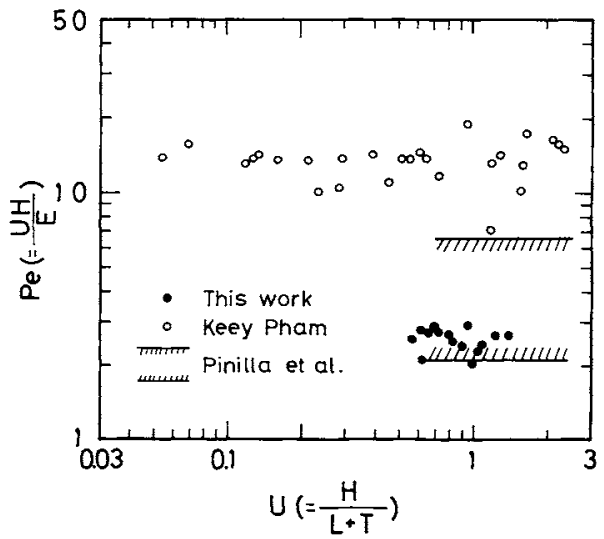

Fig. 3. Dependence of airflow Peclet number on characteristic air velocity.

of characteristic velocity in the report of Pinilla et al. ${ }^{3)}$ is not clear, only the level of Peclet number is cited from Pinilla et al. Keey and Pham used a tall spray chamber, and recirculating flow was carefully avoided in their experiment. Thus the higher value of Peclet number is convincing. As already reported by the present authors, ${ }^{4)}$ a strong recirculating flow was observed in the spray-drying chamber of this work. This seems to cause the lower value of Peclet number. The spray tower used by Pinilla et al. was a countercurrent type. Although a detailed description of flow characteristics is not available, their data show intermediate behaviour between those of Keey and Pham and the present work. All the data show that the experimentally determined Peclet number is independent of the characteristic velocity. Pinilla et al. showed that the Peclet number for gas flow is almost the same as that for liquid droplets. Thus, it might be concluded that the results shown in Table 1 are useful for prediction of the residence-time distribution of atomized droplets in a spray-drying chamber.

\section{Conclusion}

Residence-time distribution of air in a spray-drying chamber was experimentally determined. The transfer function for the response of air temperature perturbation was simulated, using the series combination model of a piston flow and a perfect mixing. From the experimental results of residence-time distribution, the Peclet number in a spray-drying chamber was determined. These data are expected to be most useful for analysis of the drying mechanism of atomized droplets in a spray dryer.

\section{Nomenclature}

$E \quad=$ back-mixing diffusion coefficient $\quad\left[\mathrm{m}^{2} / \mathrm{s}\right]$

$G(s) \quad=$ transfer function $\quad[--]$

$H \quad=$ height of spray chamber [m]

$L \quad=$ delay time for piston flow element [s] 


$\begin{array}{llr}P e & =\text { Peclet number } & {[-]} \\ s & =\text { Laplace transform parameter } & {\left[\mathrm{s}^{-1}\right]} \\ T & =\text { time constant for complete mixing element } & {[\mathrm{s}]} \\ U & & \text { characteristic velocity } \\ U_{0} & & {[\mathrm{~m} / \mathrm{s}]} \\ & \text { mean velocity at inlet section } & {[\mathrm{m} / \mathrm{s}]}\end{array}$

1) Eguchi, W.: Kagaku Kögaku, 26, 947 (1962).

2) Keey, R. B. and Q. T. Pham: Chem. Eng. Sci., 32, 1219 (1977).

3) Pinilla, E. A., J. M. Diaz and J. Coca: Can. J. Chem. Eng., 62, 617 (1984).

4) Usui, H., Y. Sano, Y. Yanagimoto and Y. Yamasaki: $J$. Chem. Eng. Japan, 18, 243 (1985).

\title{
FLOW CHARACTERISTICS OF DOWNFLOW BUBBLE COLUMNS WITH GAS ENTRAINMENT BY A LIQUID JET
}

\author{
AKIrA OHKAWA, YoShiHIRo SHIOKAWA, NOBUYUKi SAKAI AND HiRoshi IMAI \\ Department of Chemical Engineering, Nitgata University, Niigata 950-21
}

Key Words: Gas Entrainment Rate, Gas Holdup, Downflow Bubble Column, Liquid Jet, Chemical Reactor

The features of the downflow bubble column with gas entrainment by a liquid jet, in which an air compressor is unnecessary and the make-up of the closed system is facilitated, were demonstrated in a previous paper. ${ }^{6)}$ The main objective of the present study is to clarify the flow regimes of gas and liquid in this downflow system, and to obtain correlations useful in predicting gas holdup and gas entrainment rate under bubbling downflow conditions.

\section{Experimental}

The experimental apparatus (Fig. 1) and methods employed in this study were the same as in the previous work. ${ }^{6)}$ The aerated liquid height $H_{f}$ from the lower end of the column was held constant at $2.0 \mathrm{~m}$, but the diameters of the column and nozzle or the liquid jet length were varied within the range shown in Table 1. Concerning the gas entrainment rate, in addition to the volumetric rate $Q_{e}$ of gas entrained through the column, the total volumetric rate $Q_{T}$ of gas entrained by the liquid jet, which is the sum of $Q_{e}$ and the volumetric rate $Q_{o}$ of gas leaving the liquid surface in the column, was also measured. After both the gases separated in the separation tank and left from the liquid surface were introduced into a replacement vessel, $Q_{T}$ was determined by using the same method as described previously. ${ }^{4,6)}$ All the experiments were carried out with the liquid phase being water and the gas phase being air. The experimental conditions and corresponding keys used in

Received March 4, 1985. Correspondence concerning this article should be addressed to A. Ohkawa. H. Imai is now at Dept. of Chem. Proc. Eng., Hokkaido Univ., Sapporo 060 . figures are summarized in Table 1.

\section{Results and Discussion}

2.1 The flow behavior of gas and liquid in the column and the criterion of flow regimes

In the previous paper, ${ }^{6)}$ it was shown that with increasing liquid velocity $U_{l}$ four types of flow regimes were observed in the column: (A) bubble stagnant flow, (B) ununiform bubbling flow, (C) uniform bubbling flow and (D) churn-turbulent flow, in which, due to the increased amount of entrained air, coalescence of bubbles occurs, leading to the reduction of gas holdup. Of these flow regimes, the flow pattern effective for gas-liquid contacting is regime $(\mathrm{C})$, where the bubbles formed in the liquid by the jet flowdown

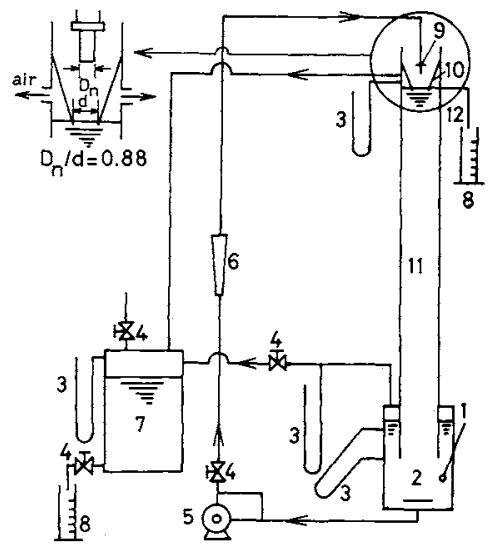

Fig. 1. Experimental apparatus: 1, thermometer; 2, separation tank; 3 , manometer; 4 , valve; 5 , pump; 6 , flow meter; 7 , replacement vessel; 8 , measuring cylinder; 9 , nozzle; 10, cap; 11, column; 12, overflow tube. 